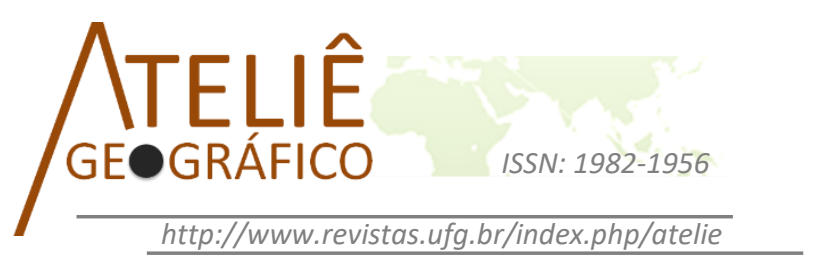

\title{
Turismo y acumulación por desposesión en Cozumel, México
}

\author{
Tourism and accumulation by dispossession in Cozumel, Mexico
}

Turismo e acumulação por espoliação em Cozumel, México

\author{
Alejandro Palafox-Muñoz \\ Universidad de Quintana Roo \\ alejandro.palafox.munoz@gmail.com
}

Stephanie Bolan-Sorchini

Universidad de Quintana Roo

s.bolan@hotmail.com

\begin{abstract}
Resumen
La acumulación por desposesión es una estrategia utilizada por el Estado para fortalecer el modo de producción capitalista, el cual resguarda los intereses del capital mediante la apropiación de los espacios naturales y culturales para el desarrollo del turismo. El valor de uso de los bienes comunes se incrementa por la capacidad que el turismo tiene para generar riqueza, en suma, al interés por espacios de recreo con características vinculadas a la naturaleza, con paisajes y escenarios prístinos, es decir, ambientes disímiles a los relacionados con su vida cotidiana. Por ello, numerosos actores ajenos al sitio de origen toman el poder del territorio, en donde se desarrollan múltiples actividades de los actores locales, transformando el sitio hasta convertirlo en un nuevo espacio vinculado al turismo, los desarrollos inmobiliarios, los espacios recreativos, entre otros. El beneficio está destinado a los nuevos propietarios de los medios de producción, despojando a las comunidades de su territorio y de los elementos que le permitan integrarse a la dinámica del mercado.
\end{abstract}

Palabras clave: Acumulación por desposesión; turismo; Cozumel.

\begin{abstract}
Accumulation by dispossession is a strategy used by Government to strengthen the capitalist mode of production, which protects the interests of private companies and investors betting on the natural and cultural areas whose economic value is increased by the ability of tourism has to generate wealth from the interest of people for recreational spaces with characteristics linked to nature, pristine landscapes and scenarios, ie dissimilar to those related to their daily life environments. Therefore, many actors outside the site of origin took power in the
\end{abstract}


territory, where many activities of local actors are developed, transforming the site into a new space, to generate related dynamics tourism, real estate development, recreational spaces among others bringing benefits to the new owners of the means of production, stripping communities without property and elements to be inserted into the dynamics of the market.

Keywords: Accumulation by dispossession; Tourism; Cozumel.

\begin{abstract}
Resumo
Acumulação por espoliação é uma estratégia utilizada pelo Estado para fortalecer o modo de produção capitalista, que protege os interesses do capital mediante a apropriação de espaços naturais e culturais para o desenvolvimento do turismo. $\mathrm{O}$ valor de uso dos bens comuns é aumentada pela capacidade do turismo para gerar riqueza, além de interesse em áreas de lazer com características ligadas à natureza, paisagens e as configurações intactas, ou seja, ambientes diferentes relacionados com suas vidas diárias. Por isso, muitos atores de fora do local de origem tomou o poder no território, onde muitas atividades de jogadores locais a desenvolver, transformando o local para se tornar um novo espaço relacionadas com o turismo, desenvolvimento imobiliário, áreas de lazer, etc. O benefício é destinado para os novos proprietários dos meios de produção, privando as comunidades de seu território e os elementos que lhes permitam integrar a dinâmica do mercado.
\end{abstract}

Palavras-chave: Acumulação por expropriação; Turismo; Cozumel.

\title{
Introducción
}

El turismo se le reconoce principalmente por sus beneficios económicos y generación de empleos, al menos en el discurso asociado al modo de producción capitalista impulsado por los Estados neoliberales y expandido a través de las estrategias globalizadoras de la economía, dada su relevancia e interés del capital por la sobreacumulación propia del modelo. En México, el turismo es una de las actividades económicas de mayor aporte al Producto Interno Bruto 2.0\% (SECTUR, 2017). El estado de Quintana Roo contribuye con $43.9 \%$ (\$8,602.48 mdd) de la derrama económica correspondiente al turismo internacional, siendo Cancún y la Riviera Maya sus destinos más importantes los cuales concentran $87.9 \%$ de la infraestructura hotelera de la entidad y $89.7 \%$ de los ingresos económicos.

No obstante, la isla de Cozumel se ha posicionado como un destino estratégico en el segmento de turismo de cruceros, buceo y deportivo generando una derrama económica en 2016 de \%710.57 mdd. Sin embargo, alcanzar dicha acumulación de riqueza ha requerido de un proceso conocido en la literatura académica como acumulación por despojo (Harvey, 2004), utilizado en la literatura académica de corte crítico y en suma al aporte de Vilchis y colaboradores (2016) con las dinámicas de acumulación (penetración, subsunción y cercamientos), se realiza el análisis del proceso de acumulación por despojo a través de la actividad turística. 
Cozumel, destino turístico en la zona del Caribe, segmentado por su demanda relacionada con: a) cruceros; b) buceo; y c) deporte extremo, ha mostrado un desarrollo que pasa por varias etapas, la primera vinculada al buceo, sin embargo con las políticas turísticas vinculadas a la captación masiva de viajeros, el destino fue reorientado hacia el turismo de cruceros para lo cual, hoy en día cuenta con tres muelles para la recepción de nueve navíos, más aquellos que se sitúen alrededor de la costa. Finalmente, el turismo deportivo ha logrado posicionarse en la temporada baja de la zona, ya que está directamente relacionada con los aspectos climáticos (lluvias y temporada de ciclones tropicales), que sin duda afectan el desarrollo de la temporada, sin embargo este segmento de mercado ha dado lugar a eventos de carácter internacional tales como: a) Ironman; b) 70.1 o medio Ironman; c) Triatlón; d) Gran Fondo de Nueva York; dichas eventos deportivos se celebran durante los meses de septiembre, octubre y noviembre.

El turismo, ha requerido de la transformación física e ideológica de la localidad, a fin de poder contar con el apoyo de la población para la aceptación y promoción de la actividad turística como eje económico de la localidad y de la entidad. Lamentablemente, el despojo ha sido paulatino y el crecimiento y concentración del capital está asociado a un pequeño sector de la población, el cual está vinculado al aparato político del país, el estado y municipio.

\section{La acumulación por desposesión}

El proceso de acumulación y reproducción del capital, David Harvey (2004) lo separa en dos modalidades: la acumulación ampliada ${ }^{1}$ y la acumulación por desposesión. La primera se da en espacios sociales en los que existe el capitalismo, en donde concurren mercados competitivos en instituciones de propiedad privada, jurídica y libertad contractual, además de las estructuras legales garantizadas por el Estado, quién asegura la estabilidad en la que se producen, intercambian y circulan mercancías. Así mismo, los conflictos son entre el capital y el trabajo o entre el capital y capital, sobre todo en lo relacionado a los monopolios, la apertura del mercado, el reparto de utilidades, la competencia, entre otras. La segunda, se refiere a la expansión del capital por medio del despojo, de tipo legal o ilegal, del patrimonio de uso común de las zonas rurales. Esta acumulación se refiere a la negación de los derechos o arreglos sociales que generen un conflicto entre los actores sociales que se resistan a la desposesión.

De acuerdo con Merchand (2013), la acumulación por desposesión es la instrumentación del Estado y los dueños del capital sobre el interés común, debido a "la necesidad del capital por conquistar nuevos espacios lo que hace indispensable el papel del Estado para resguardar dichas inversiones" (p.108), por tanto, el despojo es un

\footnotetext{
${ }^{1}$ Es cuando parte de la plusvalía se capitaliza y se emplea adquirir fuerza de trabajo y medios de producción, como consecuencia se tiene la acumulación de capital (MARX, 1999).
} 
elemento central de la acumulación capitalista (COMPOSTO \& NAVARRO, 2012) principalmente en lo relacionado con la naturaleza y los espacios comunales con el propósito de convertirlos en productos rentables, logrando de esta manera afianzarse como mecanismo de expansión del modo de producción capitalista.

A partir del modelo capitalista de orden neoliberal, el Estado interviene claramente en el proceso de desposesión mediante la oferta de libertad (DE SOUSA, 2003 citado en GÓMEZ, 2015) y ejerce control de las sociedades mediante la imposición de políticas tendientes con el mercado y sus necesidades (BOJÓRQUEZ \& ÁNGELES, 2014) con el objetivo de establecer las condiciones que los Organismos Internacionales (OI) exigen para que los Estados en desarrollo inserten en el marco de su política económica, las pautas de libre mercado y exención de aranceles, para ello, el Estado establece el marco legal para alcanzar el objetivo de reproducir el capital como modo de vida.

En este sentido, Harvey (2004) plantea que la incapacidad de acumular a través de la reproducción ampliada viene acompañada de intentos progresivos por acaparar mediante la desposesión, a este proceso le llama nuevo imperialismo. Por tanto, la sobreacumulación supone un excedente de trabajo y de capital, dicha abundancia puede ser utilizada para la apertura de nuevos mercados en otros territorios, aunque, estos nuevos mercados deben tener excedentes en oro, dinero o cualquier otra forma que sirva como medio de pago. Por lo tanto, se presenta una nueva ola de cercamiento de los comunes con la ayuda del Estado y en contra de la voluntad popular (Ídem, 2003).

Se puede hablar de acumulación por desposesión desde la expropiación violenta de los productores en el momento en que se formó el capitalismo y no sólo con este hecho, sino que también se promueve en todos los lugares en donde el capitalismo sigue presentándose como un mecanismo de funcionamiento, en el cual su expansión abarca todo el mundo (VEGA, 2012). Por ello, los Estados subdesarrollados o sin capacidad económica para buscar la compra de excedentes, recurren a los OI como el Fondo Monetario Internacional (FMI) o el Banco Mundial (BM) para recibir crédito o asistencia y poder adquirir las mercancías generadas en su propio territorio (HARVEY, 2004). De esta manera, los propietarios de los medios de producción están generando capital excedente a través de relaciones de producción con base en la desposesión, ya que se están utilizando los recursos del territorio donde se encuentra la fuerza de trabajo, modificando las relaciones sociales de producción incluyendo a la mujer en la economía productiva y aumentando su presencia en ella (EZQUERRA, 2012).

Asimismo, Galafassi (2010) menciona que el despojo es el proceso por el que las nuevas formas de capital se expanden sobre las formas de desarrollo regional sean capitalistas o no, recolonizando y redefiniendo a la explotación de recursos y las prácticas utilizadas para su depredación. Del mismo modo, Gowan (1999) afirma que la acumulación por desposesión es un instrumento de gobernanza y control económico para impulsar el proceso de globalización y las transformación neoliberal, lo que ha forzado 
la apertura de mercados, por ello la insistencia de que el Estado prepara las condiciones para la reproducción del modelo neoliberal.

A pesar del argumento sobre el libre comercio de mercancías, las acciones lo desmienten al incrementarse el poder monopólico u oligopólico del sector turístico, entre otros, tal como describen Palafox y otros (2010) en el caso del sector hotelero en México; Palafox (2010 y 2013) afirma que el turismo se constituye como un eje de acumulación; Bojórquez y Ángeles (2014) analizando la expansión turística en Los Cabos; Vilchis y otros (2016) con la mercantilización de la naturaleza, Bojórquez (2016) sobre la apropiación del patrimonio cultural, y Cañada (2016) menciona las implicaciones socioambientales de la construcción del espacio turístico.

La política neoliberal que implica la privatización, así como la posterior mercantilización del territorio, las estructuras de poder, los mecanismos y las formas en las que se les permite a los intereses económicos ser impuestos por las élites mediante la subsunción de los actores locales, ya que "el territorio es valorado por el capital como recurso" (GOTTMAN, 1975 citado en GÓMEZ, 2015: 121).

Para Garibay (2010), la desposesión es la negación de los derechos que fueron heredados de generación en generación, la movilización del poder para desintegrar los arreglos sociales anteriores, la imposición de una nueva forma de organización social, así como de los conflictos a partir de las iniciativas y formas de la apropiación de espacios sociales que no son originarios frente a grupos sociales que se resisten ante la desposesión de dicho territorio y el posterior uso distinto al que se llevaba a cabo. Así mismo lo plantea Malinowski (1966 citado en GUERRA \& SKEWES 2010: 452) "al remover a un ser humano de su ambiente social, ipso facto se le priva de todo su soporte moral, eficiencia económica e incluso interés por la vida".

Harvey (2004) señala una nueva forma de imperialismo capitalista con la acumulación por desposesión, la privatización, así como la mercantilización del territorio y la expulsión por la fuerza de las poblaciones campesinas, al convertir los derechos de propiedad ya sea comunal, colectiva, estatal entre otras, en derechos de propiedad exclusivos y la opresión de las formas alternativas de producción y consumo como diversas formas de acumulación. Alcanzar la acumulación por medio de la desposesión requiere del saqueo y degradación del entorno natural y cultural, ya que "la concentración de tierras en manos de muy pocos terratenientes ha sido una característica distintiva de la historia" (VEGA, 2012:3).

Después de los procesos fallidos de industrialización y liberación nacional en las décadas de los cincuenta y sesenta, los países del tercer mundo se convierten en países creadores de materias primas, minerales, biodiversidad y alimentos bajo el esquema de aprovechamiento de oportunidades en el marco de una crisis ambiental (MACHADO, 2010; GALAFASSI, 2010); por ejemplo, Argentina vendió sus principales empresas productoras de bienes y servicios, a fin de contar con bonos de la deuda externa y la subvaluación de activos de los sectores siderúrgico, energético, vial ferroviario, bancario y servicios públicos (GÓMEZ, 2015). En este tenor, el gobierno 
colombiano modificó el uso del suelo donde existían parcelas hoy en día son carreteras; se cría ganado y el cultivo se exporta (VEGA, 2012); en medio oriente el despojo tiene un carácter geopolítico vinculado con el subsuelo, ya que esta región posee más del 50\% de las reservas de crudo y gas natural, razón por la los conflictos con Estados Unidos (TORRES, 2013) por el pensamiento hegemónico que busca la privatización y utiliza el despojo como herramienta de acumulación.

En América Latina durante los ochenta, algunos países comenzaron un proceso de descentralización de las funciones del estado para darle énfasis y prioridad a las decisiones de orden público al mercado y la ciudadanía (PAZ, 2008; TÉLLEZ, 1993; CALVA, 1988 \& PAZ, 2014), a finales de la década, el Estado Mexicano inició con algunos cambios tanto legales como institucionales con relación a las tierras y el agua, que permitieron la entrada de la propiedad social a los mercados y la transacción de los derechos que antes era imposible. En este sentido, Carrasco (2005) afirma que el proceso de apropiación es promovido por una clase política que ostenta el poder económico. De esta manera, el capital encontró la forma de llegar a las comunidades rurales y posteriormente presionarlos para permite vender su territorio, que evidentemente contaban con recursos naturales y culturales para su explotación en proyectos de diversa índole (TÉLLEZ, 1993; CALVA, 1988), por lo que Galafassi (2010) argumenta que el despojo de tierras se debe a la privatización y a la producción de mercancías.

Desde la perspectiva de los cercamientos ${ }^{2}$, la contradicción capital-naturaleza se observa que las formas de acumulación actuales involucran la depredación y las características originarias de acumulación implican situaciones y procesos de apropiación acelerada de zonas valiosas de ecosistemas, territorios y bienes comunales que aun no han sido privatizados, con el propósito de aportar al mercado mundial materias primas, así como servicios para reproducción del capital.

En este tenor, Vilchis y colaboradores (2016) proponen que el proceso de acumulación por desposesión con base en la explotación de la naturaleza establece tres tipos de dinámicas que permiten despojar de su patrimonio a las comunidades, a saber:

- De penetración: se refiere a las estructuras utilizadas para imponer un modelo de uso y aprovechamiento de los recursos por parte del Estado y los Organismos Internacionales (OI) mediante la creación y ejercicio de políticas y bases legales que flexibilizan los mercados y medios para favorecer la acumulación.

\footnotetext{
${ }^{2}$ La naturaleza constituye el insumo esencial para el desarrollo del modo de producción, constituye el soporte físico-espacial para localizar la extracción de la naturaleza, por tanto estos recursos son cercados (Galafassi, 2010).
} 
- De subsunción: en esta fase se imponen las formas de dominación y control social de una manera violenta en las comunidades. El Estado y las Organizaciones No Gubernamentales se encargan de evitar la resistencia de la gente exaltando su valor de cambio para su legitimación.

- De cercamientos: esta etapa involucra las dos fases anteriores, mediante la modificación a la normativa y envolver a las comunidades (que antes eran los actores principales) en acciones secundarias posibilitando la entrada de capitales privados, dando origen a la mercantilización de la naturaleza para la reproducción del modo de producción. Con esta fase se concluye el ciclo de desposesión al poder observar los resultados de las fases anteriores.

Sin embargo, algunos pueblos y comunidades campesinas se resisten al proceso de penetración del capital, principalmente en los países del sur, a pesar de ser amenazadas con el asalto global a los bienes de uso común (LANDER, 2010). Entre más se usufructúan los recursos naturales mayor pobreza para la población local, por tanto este modelo de explotación de la naturaleza ofrece las condiciones de rentabilidad aunque no exista desarrollo al interior del territorio y que la comunidad asentada pueda mejorar sus condiciones de vida (RODRÍGUEZ, 2010).

\section{Cozumel y la Fase de Penetración en la Acumulación por Desposesión}

Al cambiar de modelo económico por uno con características que privilegian la inversión, el libre comercio, la desregulación y la generación de plusvalía, con el propósito de establecer un proceso de acumulación ampliada, se ha cedido ante la hegemonía del modo de producción capitalista. En este sentido Harvey (2000) afirma que estas características son determinantes en la consolidación de la política económica internacional, y la desposesión se ha convertido en la condición de legitimar "la continuidad de la reproducción ampliada en los territorios del centro" (COMPOSTO \& PÉREZ, 2012: 2).

Para Smith (2005), la economía de mercado permite mejorar las condiciones de vida de la sociedad en su conjunto, sin embargo con el paso de los años y las transformaciones propias del modo de producción capitalista permean en el orbe y en la isla de Cozumel contar con recursos naturales con alto valor mercantil provocó que se posicionara como un destino turístico de tipo tradicional, con una infraestructura básica para la atención al turista pero con la tendencia comercial de las Global Commodity Chains (Cfr. Clancy, 1998), llegaron a la ínsula diversas cadenas hoteleras e inversionistas de capitales privados internacionales, situación que replicaron los capitalistas locales para el impulso a esta actividad económica.

Por ello, la historia de Cozumel y su evolución con respecto a su evolución como destino fue inminente la participación agentes privados para el crecimiento 
económico del lugar, ya que la zona costera cuenta con vastos terrenos con recursos naturales y culturales para el desarrollo del turismo, los cuales fueron adquiridos principalmente por las familias Coldwell y González (PALAFOX \& ZIZUMBO, 2009), quienes a lo largo del tiempo han consolidado los denominados Grupos Turísticos Locales (GTL), mismos que se han caracterizado por tener presencia tanto en el aparato político a nivel federal, estatal y municipal, así como una fuerte participación como empresarios locales (Cfr. PALAFOX, 2010).

Para lo anterior, era necesario el control de la tierra, por lo que de acuerdo con los datos del Registro Agrario Nacional (RAN, 1974), la isla de Cozumel contaba con $88 \%$ de su territorio bajo el dominio del ejido en el año de 1974, sin embargo vislumbrando los efectos positivos de la actividad turística generaría a futuro fortaleciendo el sector como oferta alternativa al naciente Centro Integralmente Planeado de Cancún, se expropió el 75\% de las tierras ejidales (RODRIGUES, 2015). Con el despojo de las tierras se inicia la historia del turismo en la localidad y la conformación de los Grupos Turísticos Locales (GTL) quienes al verse beneficiados con el reparto de tierras frente a la costa y la concentración de los ingresos económicos en ciertas familias (PALAFOX, 2010; RODRIGUES, 2014).

Ello tiene sustento cuando el paisaje es transformado y adquiere un valor económico (HARRIS, 1973) y como resultado se promueve la inversión, la creación de infraestructura y la apertura de fuentes de trabajo que provocaron que la población iniciara un cambio ideológico vinculado a la adopción de la actividad turística como medio de ingreso y asimilar a la isla como un destino de descanso y apto para el turismo, ya que el Estado pone de manifiesto el beneficio monetario resultado de la explotación de los recursos naturales y culturales de la localidad. En este sentido y posterior a la definición espacial de las dimensiones correctas del territorio insular, momento en el cual el ejido fue desplazado hacia el centro de la isla despojando a la comunidad del territorio costero y apropiándose de los medios de producción para la actividad turística que en ese momento era incipiente, situación que aprovecharon los empresarios locales, quienes ya habían comprado y ocupado el espacio geográfico para tal fin.

En este mismo orden de ideas, a partir de la década de los noventa, la diversificación del mercado permea sobre el destino turístico convirtiéndolo en el puerto de cruceros turísticos más importante de México, ya que en promedio recibe al año 2.53 millones de pasajeros y 510,634 turistas, lo que se traduce en 490.5 millones de dólares al año en promedio, de los cuales el turismo de cruceros aporta el $44 \%$ de los ingresos derivado del $83.2 \%$ de la demanda (Ver Figura 01). 


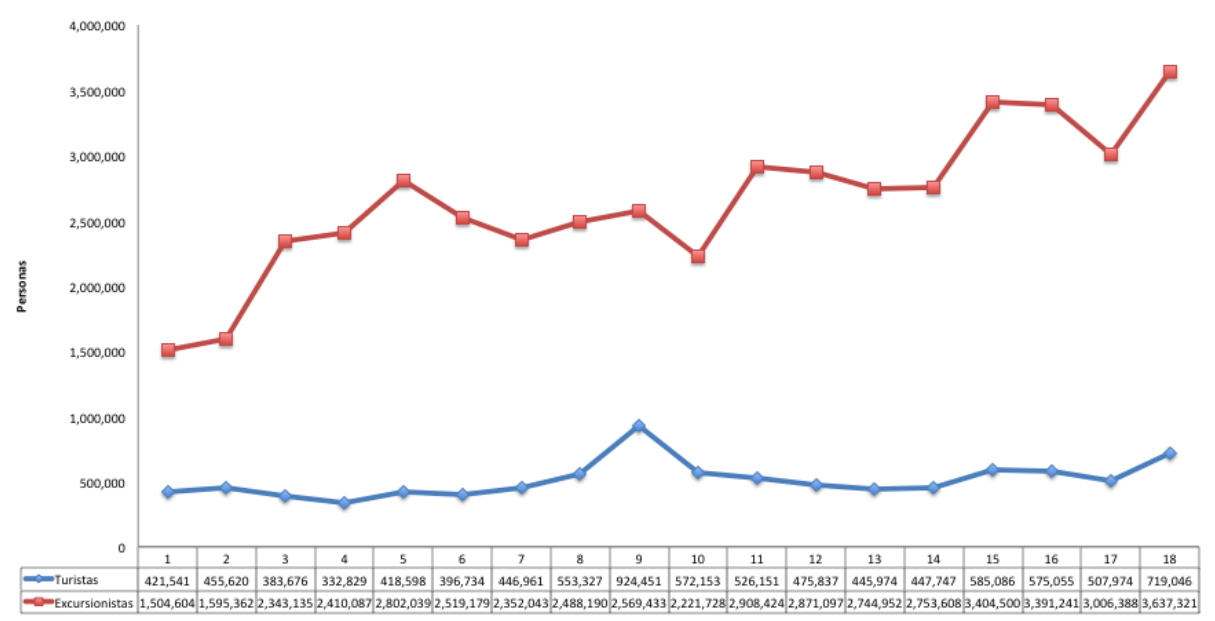

Figura 01. Turistas y excursionistas en Cozumel 2000 - 2016.

Fuente: Elaboración propia con datos de la Secretaria de Turismo del Estado de Quintana Roo (2017).

La intensidad con la que se ha desarrollado el turismo en Cozumel ha provocado varios efectos, entre ellos, el aumento en los procesos migratorios, una intensificación del espacio para uso turístico - recreativo, principalmente con la construcción de plazas comerciales para la atención a los pasajeros de cruceros, dando lugar a la subsunción del paisaje y de la población para el desarrollo turístico del territorio (Ver Foto 02).

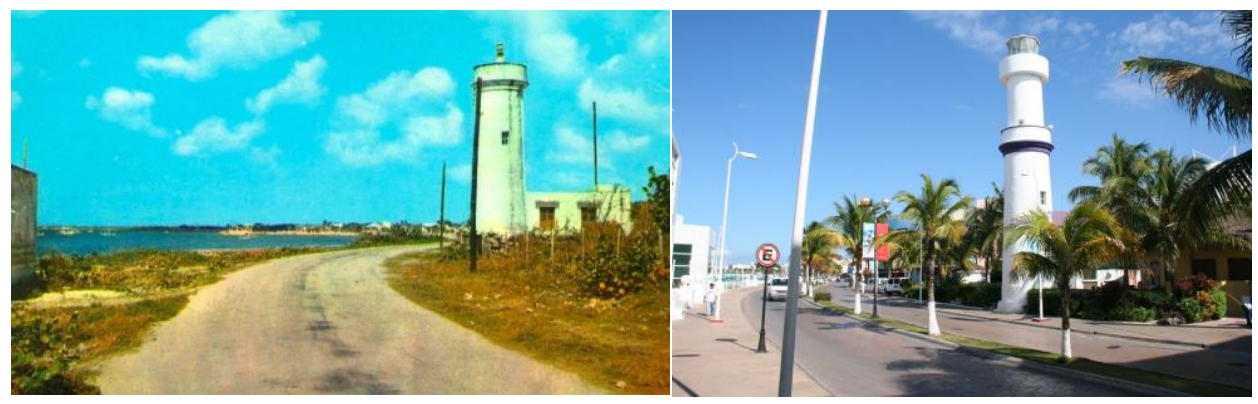

Figura 02. Punta Langosta - Plaza Punta Langosta.

Fuente: Museo de la Isla de Cozumel y colección propia.

\section{La Subsunción y su Valor de Cambio en la Isla de las Golondrinas.}

$50 \%$ de los hoteles de la ínsula son de capital mexicano, por lo cual este porcentaje muestra que la mitad de la infraestructura turística que se encuentra en las 
Zonas de Apropiación Turística (ZAT) está concesionada a empresas no provenientes de este país para el desarrollo turístico (Cfr. PALAFOX \& ZIZUMBO, 2009). Así mismo, los GTL integran diversos servicios tales como alojamiento, transportación, tour operadoras, transportadoras, entre otros, lo que les permiten ser los propietarios de los medios de producción (Cfr. PALAFOX, 2010). En este tenor, se argumenta que el turismo es un eje de acumulación económica utilizando la apertura de mercado y el libre comercio como un instrumento para la reproducción del capital, debido a que los medios de producción pertenecen a las minorías y quienes concentran el capital para su reproducción ampliada.

El termino subsunción refiere del trabajo al capital, y su adaptación al marxismo ecológico corresponde a la naturaleza subsumida a las necesidades del capital. De esta manera, Sabatella partir de la naturaleza mercantilizada, la cual no sólo provee sus valores de uso sino que por medio de ello adquiere un precio y una apropiación, en donde la naturaleza se ve como una fuerza que produce el capital en propiedad privada dejando de ser de uso común. Lo anterior se ha conseguido a través de la refuncionalización del territorio, en donde por un lado se busca terminar con la producción agrícola para dar lugar a las actividades económicas vinculadas con el sector servicios, entre las que destaca el turismo.

Zizumbo y otros (2012) mencionan que el despojo de las comunidades rurales utiliza a la sustentabilidad como política de actuación, dando al modo de producción capitalista un rostro ecológico con el cual justifica la confiscación de los recursos, la expulsión de pobladores y la creación de Áreas Naturales Protegidas para la conservación del patrimonio natural.

En Cozumel, las ANP de mayor importancia (Chankanaab y Parque Ecológico Punta Sur) son administradas por la paraestatal Fundación de Parques y Museos de Cozumel (FPMC), en donde se han establecido inversiones privadas como Dolphin Discovery, así mismo con los proyectos estatales: Chankanaab, Punta Sur y la zona arqueológica de San Gervasio, por tanto, el paisaje natural y cultural se transforma para la creación de bienes y servicios dando lugar a un paisaje de carácter económico (PALAFOX, URIBE \& ZIZUMBO, 2011). De esta manera, el turismo es un catalizador en la acumulación de capital, el cual sirve como instrumento para la apropiación de espacios, recursos y cultura, para el beneficio de las minorías mediante la transformación del valor de uso y de cambio.

\section{Los Cercamientos en la Isla de Cozumel}

La dinámica de cercamientos consiste en despojar a las personas de su tierra y reconocer solamente el derecho del capital sobre ésta y sus recursos, privándolos del uso común y transformarlo en una mercancía. No sólo se puede sustraer un espacio de tierra, sino también se sustraen los bienes del subsuelo con el argumento de que son propiedad 
del Estado, debido a ello se genera contaminación, perdida y privatización de lo que es de todos (GALAFASSI \& COMPOSTO, 2012) cosificando al recurso y desconociendo todo sentido de valor y pertenencia por parte de la comunidad.

Así, la naturaleza se torna en materia prima y se mercantiliza, por lo que las actividades primarias como la sustracción y extracción del chicle y la copra de coco que sustentaban la actividad económica, han sido suplantadas por el Estado para dar lugar al turismo, el cual se promueve de manera intensiva con el arribo de cruceros (PALAFOX, 2010). Para ello, se apropia del territorio y la comunidad con tierra con espacio costero, es desplazada al interior para no intervenir con los medios de producción capitalista. Posterior a la penetración del capital, se comercializan los recursos y el paisaje despojando a la población de todo valor desde el punto de vista cultural, social, ecológico y económico, y al ser considerado mercancía para por el capital para suministrar bienes de consumo a fin de satisfacer el disfrute o simplemente para la contemplación de la naturaleza, es necesario pagar un precio en dólares americanos. De esta manera, la población local se convierte en fuerza de trabajo, cuando antes era propietaria de los medios de producción y su vínculo con el paisaje era integral.

Por lo tanto, los cercamientos son el resultado de las dinámicas de penetración y subsunción del capital (VILCHIS, et.al; 2016), en Cozumel puede observarse el proceso que ha sufrido la isla desde sus orígenes, desde el impulso al turismo de buceo, el cual dio lugar al turismo de cruceros en donde la oferta turística alternativa se ha dedicado a satisfacer las necesidades de los pasajeros que visitan la localidad, estableciendo una dependencia económica y social a dicha actividad económica orillando a la localidad a insertarse únicamente como fuerza de trabajo a las diversas empresas dedicadas al turismo, ya que la concentración de capital está asociada a cierto número de familias, las cuales tienen el control político, territorial y económico de la localidad (Cfr. Palafox, 2010).

Evidentemente el capital no tiene límites, por lo cual el aprovechamiento a pesar de la perspectiva neocapitalista relacionada con la sustentabilidad derivada del agotamiento de los recursos, se convierte en una contradicción al ser subsumido por el capital.

\section{Consideraciones Finales}

Lo propuesto en Harvey (2004) y Vilchis con sus colaboradores (2016) sirve de referencia para comprender la realidad en la isla de Cozumel relacionada con la acumulación por desposesión, y los diversos proyectos turísticos que han sido previstos por el Estado facilitador, quién mediante la creación de políticas tanto económicas como ambientales tienen como finalidad favorecer a los interesados en invertir en dicha localidad y de esta manera continuar con el ciclo de acumulación ampliada. 
La acumulación por despojo aporta como categoría de análisis el referente teórico para el estudio del desarrollo turístico en las zonas que cuentan con los recursos natural y culturales para el desarrollo turístico desde una perspectiva crítica. Dicho proceso es promovido por los Organismos Internacionales y a través del Estado se opera con el propósito de dar continuidad a la permanencia del modo de producción capitalista, el cual establece a la acumulación ampliada como base para la política neocapitalista y establecer una hegemonía en el pensamiento y accionar de la sociedad, convirtiendo así al modo de producción capitalista en un modo de vida.

El capital en Cozumel se ha consolidado a través de la acumulación, permitiendo al poder local la creación de los Grupos Turísticos Locales, los cuales han ido abarcando una diversa gama de servicios turísticos mismos que ofrecen los bienes de consumo para la atención de la demanda, principalmente internacional y vinculada al turismo de cruceros que se desarrolla con intensidad desde hace 16 años. En este sentido, el turismo se establece como una eje de acumulación que se utiliza para el establecimiento de la hegemonía del modo de producción capitalista, toda vez que acumula capital y cosifica a la naturaleza y a las personas para la reproducción del modo de producción a través del despojo.

Por otro lado, la comunidad es involucrada en las dinámicas económicas al convertirse en fuerza de trabajo para los medios de producción, los cuales son ofertados a extranjeros, desplazándolos de sus propios bienes y teniendo que pagar para el goce y disfrute de los espacios naturales y culturales, a los cuales anteriormente tenía acceso para su recreación.

Se establece que el turismo, funciona como un eje de acumulación económica y para ello, es necesario la acumulación por desposesión, en Cozumel se presentan tres etapas para su consolidación: la penetración, la subsunción y los cercamientos. Por tanto, se plantea el supuesto de que las nuevas formas para acumular en el sector turístico, son a través de los programas gubernamentales vinculados a las Áreas Naturales Protegidas y los conocidos Pueblos Mágicos.

\section{Referencias}

ÁVILA GARCÍA, P. \& LUNA SÁNCHEZ, E. Del ecologismo de los ricos al ecologismo de los pobres. Revista Mexicana de Sociología, v. 75, n. 1, p. 63-89. 2013.

BOJÓRQUEZ LUQUE, J. \& ÁNGELES VILLA, M. Expansión turística y acumulación por desposesión: el caso de Cabo San Lucas, Baja California Sur (México). Cuadernos de Geografía / Revista Colombiana de Geografía, v. 23, n 2, p.179-202. 2014.

BOJÓRQUEZ LUQUE, J. Patrimonio histórico y acumulación por desposesión en la ciudad turística de Cabo San Lucas, Baja California Sur, México. Revista de Ciencias Sociales, n. 153, p. 153-173. 2016. 
CALVA TELLEZ, J. L. Los campesinos y su devenir en las economías de mercado. Distrito Federal: Siglo XXI. 1998

CAÑADA, E. Impactos socioambientales de la construcción del espacio turístico. Ecología Política, n. 52, p. 12-16. 2016.

CARRASCO AQUINO, R. J. La naturaleza y sus formas de apropiación en contradicción. Mundo Siglo XXI, v. 2, n. 6, p. 48-70. 2005.

CLANCY, M. Commodity Chains, services and development: theory and preliminary evidence from the tourism industry. Review of International Political Economy, v. 5, n. 1, p. 122-148. 1998.

COMPOSTO, C. \& NAVARRO, M. El despojo es una estrategia para superar la crisis de la explotación. Theomai, n. 26. 2012. Disponible en: <http://revista-

theomai.unq.edu.ar/NUMERO\%2026/Holloway\%20-\%20Entrevista.pdf> Acceso: 23 marzo 2017.

DE SOUSA SANTOS, B. La caída del Angelus Novus: ensayos para una nueva teoría social y una nueva práctica política. Bogotá: ILSA. 2003.

EZQUERRA, S. Acumulación por desposesión, género y crisis en el Estado Español. Revista de Economía Crítica, n. 14, p. 124-147. 2012.

GALAFASSI, G. Megaminería en Argentina: saqueo y nuevos cercamientos en un renovado proceso de acumulación por desposesión. In: DELGADO RAMOS, G. C. (Coord.). Ecología política de la minería en América Latina. Distrito Federal: Universidad Nacional Autónoma de México. 2010. p. 449-480.

GALAFASSI, G. \& COMPOSTO, C. Acumulación por despojo y nuevos cercamientos: el caso de la minería a gran escala en la Patagonia argentina. Cuadernos del Cendes, v. 30, n. 83, p. 75-103. 2012

GARIBAY OROZCO, C. Paisajes de acumulación minera por desposesión campesina en el México actual. In: DELGADO RAMOS, G. C. (Coord.). Ecología política de la minería en América Latina. Distrito Federal: Universidad Nacional Autónoma de México. 2010. p. 133182.

GÓMEZ LENDE, S. Orden global y acumulación por desposesión en Argentina (19902012). Finisterra, v. 50, n. 99, p. 119-141. 2015.

GOTTMAN, J. The evolution of the concept of territory. Social Science Information, v. 14, n. 3, p. 29-47. 1975.

GOWAN, P. The global gamble: Washington's bid for world dominance. London: Verso. 1999. 
GUERRA, D. \& SKEWES, J. C. Acumulación por desposesión y respuestas locales en el remodelaje de los paisajes estuariales del sur de Chile. Chungara, Revista de Antropología Chilena, v. 42, n. 2, p. 451-463. 2010.

HARRIS, M. Raza y trabajo en América Latina. Buenos Aires: Ediciones Siglo Veinte. 1973.

HARVEY, D. Mundos urbanos posibles. In: MARTÍN RAMOS, Á. (Ed.). Lo urbano en 20 autores contemporáneos. Barcelona: Universitat Politécnica de Catalunya. 2000. p. 177-197

HARVEY, D. The new imperialism. Oxford: Oxford University Press. 2003.

HARVEY, D. El "nuevo" imperialismo: la acumulación por desposesión. Social Register, n. 40, p. 99-129. 2004.

LANDER, E. Estamos viviendo una profunda crisis civilizatoria. América Latina en Movimiento, n. 452, p. 1 -3. 2010.

MACHADO AÁROZ, H. El agua vale más que el oro. Grito de resistencia descolonial contra los nuevos dispositivos expropiatorios. In: DELGADO RAMOS, G. C. (Coord.). Ecología política de la minería en América Latina. Distrito Federal: Universidad Nacional Autónoma de México. 2010. p. 59-96.

MALINOWSKI, B. Argonauts of the Western Pacific. London: Routledge \& Kean Paul. 1966.

MARX, K. El Capital. Crítica a la economía política. Tomo 1. Distrito Federal: Fondo de Cultura Económica. 1999.

MERCHAND ROJAS, M. A. El Estado en el proceso de acumulación por desposesión favorece la transnacionalización de la minería de oro y plata en México. Paradigma Económico, v. 5, n. 1, p. 107-141. 2013.

PALAFOX-MUÑOZ, A., ZIZUMBO VILLARREAL, L. \& ARRIAGA ÁLVAREZ, E. El turismo como eje de acumulación: caso del sector hotelero en México. Multiciencias, v. 10, n. 2, p. 193-201. 2010.

PALAFOX-MUÑOZ, A. \& ZIZUMBO VILLARREAL, L. Distribución territorial y turismo en Cozumel, Estado de Quintana Roo, México. Gestión Turística, n. 11, p. 69-88. 2009.

PALAFOX-MUÑOZ, A., MADRIGAL URIBE, D. \& ZIZUMBO VILLARREAL, L. Apropiación, homogenización y funcionalización del espacio para el desarrollo turístico de Quintana Roo, México. Caderno Virtual de Turismo, v. 11, n. 2, p. 282 - 293. 2011.

PALAFOX-MUÑOZ, A. Treinta años de transformaciones en Cozumel: el turismo como eje de acumulación. Revista de Economía, Sociedad, Turismo y Medio Ambiente, n. 11, p. 103122. 2010. 
PALAFOX-MUÑOZ, A. Paisaje y turismo en Cozumel. PALAFOX-MUÑOZ, A. \& ALVARADO-HERRERA, A. (Coords.), Ambientes del turismo. Actores y escenarios, Cozumel: Universidad de Quintana Roo. 2011. p. 51-68.

PALAFOX-MUÑOZ, A. El turismo como eje de acumulación. Nómadas, n. Edición Especial América Latina, p. 161-174. 2013. Disponible en:

<http://revistas.ucm.es/index.php/NOMA/article/view/42347> Acceso: 24 marzo 2017.

PAZ SALINAS, M .F. De áreas naturales protegidas y participación: convergencias y divergencias en la construcción del interés público. Nueva Antropología. Revista de Ciencias Sociales, n. 68, p. 51-74. 2008.

PAZ SALINAS, M .F. Conflictos socioambientales en México: ¿qué está en disputa? In: PAZ SALINAS, M. F. \& RISDELL, N. (Coords.). Conflictos, conflictividades y movilizaciones socioambientales en México: problemas comunes, letras diversas. Cuernavaca: CRIM-UNAM - Grupo Editorial Miguel Ángel Porrúa. 2014. p. 10-61.

RAN. Decreto de expropiación del ejido de Cozumel. Chetumal: Periódico oficial del Gobierno del Estado de Quintana Roo. Tomo II, Carpeta básica del ejido de Cozumel. 27 mayo 1974.

RODRIGUES CARVAHLO, L. Elites empresariais e configuraçao de espaços turísticos na ilha de Cozumel, México. Idéias, n. 9, 89-120. 2014.

RODRIGUES CARVAHLO, L. Expropiación de tierras ejidales como estrategia gubernamental para el desarrollo del turismo de masas en la isla de Cozumel, México. In: MARÍN GUARDADO, G. (Coord.). Sin tierras no hay paraíso. Turismo, organizaciones agrarias y apropiación territorial en México. El Sauzal (Islas Canarias): Colección Pasos Edita, 15. 2015.

RODRÍGUEZ WALLENIUS, C. Minería y respuestas sociales en Mezcala, Guerrero: un análisis desde la geopolítica local. In: DELGADO RAMOS, G. C. (Coord.). Ecología política de la minería en América Latina. Distrito Federal: Universidad Nacional Autónoma de México. 2010. p. 251-280.

SABATELLA, I. Crisis ecológica y subsunción real de la naturaleza al capital. Íconos. Revista de Ciencias Sociales, n. 36, p. 69-80. 2010.

SECTUR. Resultados de la actividad turística 2016. Ciudad de México: Secretaría de Turismo. 2017. Disponible en: <http://www.datatur.sectur.gob.mx/RAT/RAT-201612(ES).pdf> Acceso: 20 diciembre 2017.

SEDETUR. Indicadores turísticos 2017. Chetumal: Secretaría de Turismo del estado de Quintana Roo. 2016. Disponible en: < http://sedetur.qroo.gob.mx/estadisticas/indicadores/2017/Indicadores\%20Tur\%20\%20Enero\%20-\%20Diciembre\%202016.pdf> Acceso: 19 diciembre 2017

SMITH, A. The Wealth of Nations. Penssylvania: The Pennsylvania State University. 2005. 
TÉLLEZ, L. Nueva legislación de tierras, bosques y aguas. Distrito Federal: Fondo de Cultura Económica. 1993.

TORRES ALFOSEA, F. J. Aplicación del principio de acumulación por desposesión a las relaciones entre Israel y Palestina. Boletín de la Asociación de Geógrafos Españoles, n. 62, p. 147-171. 2013.

VEGA CANTOR, R. Colombia, un ejemplo contemporáneo de acumulación por desposesión. Theomai, n. 26. 2012. Disponible en: <http://revistatheomai.unq.edu.ar/NUMERO\%2026/Vega\%20Cantor\%20-\%20Colombia.pdf > Acceso: 24/03/2017.

VILCHIS ONOFRE, A., LZIZUMBO VILLARREAL, L. MONTERROSO SALVATIERRA, N. ARRIAGA ÁLVAREZ, E. \& PALAFOX-MUÑOZ, A. Dinámicas capitalistas para la acumulación por despojo. Revista de Ciencias Sociales, n. 151, p. 31-41. 2016.

ZIZUMBO VILLARREAL, L., CRUZ CORIA, E. \& VILCHIS ONOFRE, A. Acción social y Áreas Naturales Protegidas: refuncionalización de recursos en Puerto Morelos, Quintana Roo, México. Rosa dos Ventos, v. 4, n. 2, p. 192-207. 2012.

\begin{abstract}
Alejandro Palafox-Muñoz
Doctor en Ciencias Ambientales por la Universidad Autónoma del Estado de México. Se desempeña como Profesor-Investigador de Tiempo Completo en la Universidad de Quintana Roo - Unidad Académica Cozumel.

Ave. 11 esquina 110 Sur, Col. San Gervasio, Cozumel, México. C.P. 77642.

E-mail: alejandro.palafox.munoz@gmail.com

Stephanie Bolan-Sorchini

Estudiante del Doctorado en Desarrollo Sostenible y Maestra en Gestión Sustentable del Turismo por la Universidad de Quintana Roo. Se desempeña como profesora de la Universidad de Quintana Roo - Unidad Académica Playa del Carmen.

Ave. Universidad s/n frente a la Unidad Deportiva Riviera Maya. Playa del Carmen, México. C.P. 77710.

E-mail: s.bolan@hotmail.com
\end{abstract}

Recebido para publicação em maio de 2017 Aprovado para publicação em janeiro de 2018 